\title{
ACÚMULO DE BIOMASSA EM FUNÇÃO DE DOSES DE FÓSFORO E INOCULAÇÃO DE RIZÓBIO EM FEIJÃO-CAUPI
}

\author{
Weslany Silva Rocha ${ }^{1}$, Mauro Gomes dos Santos ${ }^{1}$, Tânia Rodrigues Peixoto Sakai ${ }^{2}$, Taynara \\ Alves da Silva ${ }^{2}$, Rodrigo Ribeiro Fidelis ${ }^{3}$, Manoel Mota dos Santos ${ }^{3}$ \\ ${ }^{1}$ Doutorando em Produção Vegetal pela Universidade Federal do Tocantins, Gurupi - TO. E-mail: \\ weslanyagro@gmail.com,maurogomes@ifto.edu.br \\ 2 Graduanda em Agronomia pela Universidade Federal do Tocantins, Gurupi - TO. E-mail: \\ sakaipeixoto2012@hotmail.com; tay325@gmail.com \\ 3 Prof. Dr. do curso de Agronomia da Universidade Federal do Tocantins, Gurupi - TO. E-mail: \\ fidelisrr@uft.edu.br; santosmm@uft.edu.br
}

RESUMO: Estudos envolvendo a influência de doses de fósforo e avaliações do potencial simbiótico do rizóbio são escassos e indispensáveis para recomendações no manejo da cultura. Objetivou-se avaliar a biomassa de feijão-caupi em função das doses de fósforo, com e sem inoculação, em casa de vegetação e campo. Os experimentos foram conduzidos, em 2014/15 na Universidade Federal do Tocantins, com a cultivar BRS Novaera. O delineamento experimental foi inteiramente casualizado (DIC) com três repetições em casa de vegetação e blocos casualizados (DBC) com quatro repetições em campo, em fatorial (2x6) sendo o primeiro (com e sem inoculação) e o segundo seis doses de fósforo $(0,30,60$, 90,120 e $150 \mathrm{~kg} \mathrm{ha}^{-1}$ de $\mathrm{P}_{2} \mathrm{O}_{5}$ ), totalizando 12 tratamentos. Foram avaliadas a massa seca da parte aérea, massa seca das raízes, número de nódulos e massa seca dos nódulos. Em casa de vegetação a inoculação com rizóbio apresentou resposta linear para a massa seca da parte aérea. Em campo a massa seca da parte aérea houve efeito quadrático e máximo de 48,51 g na dose de $60 \mathrm{~kg} \mathrm{ha}^{-1}$ de $\mathrm{P}_{2} \mathrm{O}_{5}$ sem inoculação. O número e massa seca de nódulos foram

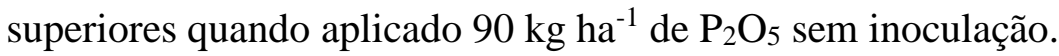

Palavras-chave: Promoção crescimento. $\mathrm{P}_{2} \mathrm{O}_{5}$. Simbiose. Vigna unguiculata.

\section{BIOMASS ACCUMULATION AS A FUNCTION OF PHOSPHORUS DOSES AND INOCULATION OF RHIZOBIUM IN COWPEA}

\begin{abstract}
Studies involving the influence of phosphorus doses and evaluation of symbiotic potential of rhizobium are scarce and indispensable for recommendations on crop management. The objective of this study was to evaluate the biomass of cowpea as a function of the doses of phosphorus, with and without inoculation, in greenhouse and field. The experiments were conducted in 2014/15 at the Federal University of Tocantins, with the BRS Novaera variety. The experimental design was completely randomized (CI) with three replications in a greenhouse and randomized blocks (DBC) with four replications in the field, in factorial (2x6), the first one (with and without inoculation) and the second six doses of phosphorus $0,30,60,90,120$ and $150 \mathrm{~kg} \mathrm{ha}^{-1}$ of $\mathrm{P}_{2} \mathrm{O}_{5}$ ), totaling 12 treatments. The dry
\end{abstract}


mass of the aerial part, dry mass of the roots, number of nodules and dry mass of the nodules were evaluated In greenhouse the inoculation with rhizobia showed a linear response to the dry mass of the aerial part. In the field, the dry mass of the shoot was quadratic and maximum effect of $48.51 \mathrm{~g}$ in the dose of $60 \mathrm{~kg} \mathrm{ha}^{-1}$ of $\mathrm{P}_{2} \mathrm{O}_{5}$ without inoculation. The number and dry mass of nodules were higher when $90 \mathrm{~kg} \mathrm{ha}^{-1}$ of $\mathrm{P}_{2} \mathrm{O}_{5}$ was applied without inoculation.

Key words: Growth promotion. $\mathrm{P}_{2} \mathrm{O}_{5}$. Symbiosis. Vigna unguiculata.

\section{INTRODUÇÃO}

O feijão-caupi (Vigna unguiculata (L.) Walp) é uma leguminosa comestível, dotada de alto conteúdo protéico, com boa capacidade de fixar nitrogênio e pouco exigente em fertilidade do solo. É cultivado predominantemente por pequenos produtores nas regiões Norte e Nordeste do Brasil (SILVA et al., 2010).

Embora a cultura apresente boa capacidade de fixar nitrogênio (FBN) pela simbiose com bactérias, nem sempre são observadas respostas positivas do uso de inoculantes em campo, em razão do feijão-caupi ser cultivado, na maioria das vezes, em condições de subsistência com baixo aporte tecnológico e apresentar baixa especificidade na nodulação (ZILLI et al., 2008).

A eficiência do processo de fixação do $\mathrm{N}_{2}$ é dependente da disponibilidade de $\mathrm{P}$ devido a sua participação no processo simbiótico (BURITY et al., 2000).

Além disso, o $\mathrm{P}$ promove o aumento da produção de matéria seca da parte aérea, incremento do número de vagens e massa de grãos (FAGERIA et al., 2003). A adubação fosfatada também aumenta o teor e acúmulo de $\mathrm{P}$ na matéria seca da parte aérea e nos grãos (FONSECA et al., 2010).

Porém no cerrado, tocantinense, a técnica da inoculação com rizóbios na cultura do feijão-caupi ainda é pouco utilizada, apesar do estado se encontrar na região de fronteira agrícola (MATOPIBA), necessita-se investimentos em pesquisas de avaliação da FBN na cultura do feijão-caupi e da eficiência simbiótica de estirpes de rizóbio nas condições de clima e solo da região de Gurupi - TO.

Então diante do exposto, objetivou-se avaliar a produção de biomassa de feijão-caupi em função das doses de fósforo, com e sem inoculação, em casa de vegetação e campo na safra 2014/15, no sul do estado do Tocantins.

\section{MATERIAL E MÉTODOS}

Os experimentos foram conduzidos, na Estação Experimental do campus de Gurupi, da Universidade Federal do Tocantins em casa de vegetação e no campo do ano agrícola 
2014/15, caracterizada pelas coordenadas geográficas $11^{\circ} 43^{\prime}$ de latitude sul e $49^{\circ} 15^{\prime}$ de longitude oeste, numa altitude de $300 \mathrm{~m}$, em solo do tipo Latossolo vermelho-amarelo distrófico (SANTOS et al., 2013) e a caracterização climática local é de clima tropical úmido com pequena deficiência hídrica (B1wA'a') conforme classificação Tornthwaite. A precipitação pluviométrica média foi em torno de $5 \mathrm{~mm}$, temperatura média de $27^{\circ} \mathrm{C}$ e umidade relativa $83 \%$ no período dos experimentos conforme a estação meteorológica do campus de Gurupi- TO da UFT/INMET, 2014/15.

A análise química e granulométrica dos solos de ambos experimentos, foi realizada na camada de 0-20 cm de profundidade da área experimental aproximadamente 30 dias antes da semeadura, sendo $\mathrm{pH}$ em $\mathrm{CaCl}_{2}: 5,1 ; \mathrm{H}+\mathrm{Al}: 3,40 \mathrm{cmol}_{\mathrm{c}} \mathrm{dm}^{-3} ; \mathrm{Ca}: 2,2 \mathrm{cmol}_{\mathrm{c}} \mathrm{dm}^{-3} ; \mathrm{Mg}$ : 0,7 $\mathrm{cmol}_{\mathrm{c}} \mathrm{dm}^{-3} ; \mathrm{K}: 0,10 \mathrm{cmol}_{\mathrm{c}} \mathrm{dm}^{-3} ; \mathrm{S}: 2 \mathrm{mg} \mathrm{dm}^{-3}$; P (mehlich I): 0,5 mg dm${ }^{-3}$; CTC: 6,40 cmol $_{\mathrm{c}} \mathrm{dm}^{-3}$; V\%: 47; Matéria Orgânica: 2,4 dag kg-1; argila: $285 \mathrm{~g} \mathrm{~kg}^{-1}$; silte $37 \mathrm{~g} \mathrm{~kg}^{-1}$; areia $678 \mathrm{~g} \mathrm{~kg}^{-1}$. Promoveu-se a calagem utilizando o calcário dolomítico com 6-10\% MgO e PRNT 80-85\%, utilizando-se a metodologia de saturação de cálcio e magnésio, com aplicação de $3 \mathrm{t} \mathrm{ha}^{-1}$ somente para o experimento realizado em campo.

Foi utilizada a cultivar BRS Novaera para ambos experimentos, que possui hábito de crescimento indeterminado, porte semi - ereto, ciclo de 65 - 70 dias e cor da flor branca (EMBRAPA, 2007).

O delineamento experimental foi inteiramente casualizado (DIC) em casa de vegetação e blocos casualizados (DBC) em condições de campo, em arranjo fatorial $(2 \times 6)$ sendo o primeiro fator (com e sem inoculação) e o segundo fator seis doses de fósforo ( 0 , $30,60,90,120$ e $150 \mathrm{~kg} \mathrm{ha}^{-1}$ de $\mathrm{P}_{2} \mathrm{O}_{5}$ ), totalizando 12 tratamentos, com três repetições em casa de vegetação e quatro em campo. Neste foi fornecido também adubação complementar de $60 \mathrm{~kg} \mathrm{ha}^{-1} \mathrm{~K}_{2} \mathrm{O}$ fonte cloreto de potássio e $20 \mathrm{~kg} \mathrm{ha}^{-1}$ de $\mathrm{N}$ com fonte ureia na semeadura. As referidas doses de fósforo foram calculadas de acordo com o volume de solo do vaso.

A inoculação foi realizada com a estirpe INPA 03-11B do gênero Bradyrhizobium japonicum, obtida junto ao Laboratório de Microbiologia da Universidade Federal de Lavras (Minas Gerais, Brasil), recomendada para a cultura do feijão-caupi, isolada em meio YMA (VINCENT, 1970) e mantidas sob refrigeração (a $4{ }^{\circ} \mathrm{C}$ ).

Em casa de vegetação foram utilizados vasos para a semeadura de cinco sementes por vaso, sendo estes com capacidade de $4 \mathrm{~L}\left(0,004 \mathrm{~m}^{3}\right)$ de solo. O preparo dos vasos com solo de uma área com histórico de cultivo de pastagem, onde nunca se promoveu inoculação antes, consistiu em peneirar o solo (peneira $4 \mathrm{~mm}$ de malha) e tratamento para esterilização de microrganismo em autoclave por 1 hora, a pressão de $1,5 \mathrm{~kg} \mathrm{~cm}^{-2}$ a $127^{\circ} \mathrm{C}$. $\mathrm{O}$ tratamento de sementes foi realizado utilizando inseticida com o principio ativo tiametoxam, grupo químico dos neonicotinóides e com recomendações para a cultura de 200 a 300 ml para 100 $\mathrm{kg}$ sementes. E o fungicida com o princípio ativo tiofanato metilico+fluazinam, pertencente ao grupo químico Benzimidazol (precursor de tiofanato-metílico) e fenilpiridinilamina (percursor de fluazinam), com recomendações para a cultura de 145 a $180 \mathrm{ml}$ para $100 \mathrm{~kg}$ de

Cultura Agronômica, Ilha Solteira, v.27, n.2, p.273-286, 2018 
sementes. A semeadura foi manual com cinco sementes por vaso, com inoculação de $100 \mathrm{ml}$ de solução de $\mathrm{NaCl}$ a $0,2 \%$, com concentração de $10^{8}$ células $\mathrm{ml}^{-1}$, com as estirpes na fase $\log$ de seu crescimento (quatro dias de cultivo a $28^{\circ} \mathrm{C}$ ) uma hora antes da semeadura.

O desbaste ocorreu aos 12 dias após a emergência deixando-se duas plantas por vaso. A irrigação foi manual com o auxílio de um copo graduado, oferecendo água para as plantas até a capacidade de solo.

As adubações de cobertura consistiram em acrescentar $30 \mathrm{~kg} \mathrm{ha}^{-1} \mathrm{~N}$, aos 25 dias após emergência (25 DAE) para todos os tratamentos.

As plantas foram colhidas manualmente no estádio de florescimento, duas plantas por vaso. Após o destacamento manual, os nódulos das raízes foram contados obtendo-se o número de nódulos, e assim como a parte aérea, foi acondicionada em sacos de papel e levados para uma estufa de circulação forçada $\left(65\right.$ a $\left.70^{\circ} \mathrm{C}\right)$ até o peso constante para avaliação da massa seca da parte aérea, massa seca das raízes, massa seca dos nódulos, obtidos com o auxílio de balança de precisão $(0,01 \mathrm{~g})$.

Em campo o preparo do solo foi realizado de forma convencional, com uma gradagem (25”) e uma gradagem para nivelamento da área (16”) e posterior sulcamento do solo. A unidade experimental foi constituída de quatro linhas de $5 \mathrm{~m}$ de comprimento, espaçadas 0,50 m entrelinhas totalizando uma área de $10 \mathrm{~m}^{2}$. Os dados de componentes da produção foram obtidos nas duas linhas centrais, com área útil de $4,0 \mathrm{~m}^{2}$, excluindo as bordaduras, formada pelas linhas externas e meio metro das extremidades das linhas centrais. A semeadura foi manual, no mês de novembro com a inoculação da estirpe de rizóbio INPA 03-11B (Bradyrhizobium japonicum). Após crescimento em meio YMA (extrato de levedura, manitol, ágar) por cinco dias, foi suspensa em solução salina $\left(0,2 \% \mathrm{MgSO}_{4}\right)$ e adicionada na concentração de $10^{9}$ células $\mathrm{mL}^{-1}$ cada, às sementes uma hora antes da semeadura, sendo utilizada $50 \mathrm{~mL} \mathrm{~kg}^{-1}$ de semente.

Neste foi fornecido também adubação complementar de $60 \mathrm{~kg} \mathrm{ha}^{-1} \mathrm{~K}_{2} \mathrm{O}$ com fonte cloreto de potássio e $20 \mathrm{~kg} \mathrm{ha}^{-1}$ de $\mathrm{N}$ com fonte ureia na semeadura.

As adubações de cobertura foram parceladas em duas vezes para todos os tratamentos aos 15 DAE e aos 30 DAE, cada uma de $30 \mathrm{~kg} \mathrm{ha}^{-1} \mathrm{de} \mathrm{N}$.

O manejo da cultura consistiu em capina manual e/ou aplicação de herbicidas, conforme a necessidade. O suprimento de água para a cultura foi através da água das chuvas e/ou irrigação complementar, quando necessário.

A partir do $12^{\circ}$ dia após semeadura as plantas emergidas foram desbastadas, deixando-se 10 plantas por metro linear e população de 200.000 plantas ha $^{-1}$.

Por ocasião do florescimento foi analisada a massa seca da parte aérea; estimativa da massa seca das raízes feitas com recorte de solo da área mais próxima ás raízes (trincheira); número de nódulos e massa seca dos nódulos.

Cultura Agronômica, Ilha Solteira, v.27, n.2, p.273-286, 2018 
Para ambos os experimentos a análise de variância foi realizada por meio do teste F. E para a fonte de variação doses de fósforo aplicou-se também o teste de regressão e a seleção dos modelos foram baseadas na significância dos betas e no maior coeficiente de determinação $\left(\mathrm{R}^{2}\right)$, utilizando-se o programa computacional SISVAR (FERREIRA, 2011).

\section{RESULTADOS E DISCUSSÃO}

De acordo com os resultados da análise de variância (Tabela 1), observa-se que houve efeito significativo na interação para todas as características avaliadas, evidenciando que os fatores são dependentes nas condições de casa de vegetação.

Tabela 1. Resumo da análise de variância das características massa seca da parte aérea (MSPA), massa seca da raiz (MSR), número de nódulos (NN) e massa seca dos nódulos (MSN) de feijão-caupi, submetidos a doses de fósforo com e sem inoculação em casa de vegetação. Gurupi - Tocantins, 2014.

\begin{tabular}{|c|c|c|c|c|c|}
\hline \multirow{2}{*}{ Fonte de Variação } & \multirow{2}{*}{ GL } & \multicolumn{4}{|c|}{ QM } \\
\hline & & MSPA (g) & $\operatorname{MSR}(\mathrm{g})$ & $\mathrm{NN}$ (uni) & $\mathrm{MSN}(\mathrm{g})$ \\
\hline Doses de P (D) & 5 & $2,3787 * *$ & $0,4148^{\mathrm{ns}}$ & $190,3069 * *$ & $0,0001 * *$ \\
\hline Inoculação (I) & 1 & $0,0699^{\mathrm{ns}}$ & $0,3765^{\mathrm{ns}}$ & $95,0625 * *$ & $0,00001 * *$ \\
\hline$(\mathrm{D} \times \mathrm{I})$ & 5 & $0,8926^{*}$ & $0,6894 * *$ & $84,1625^{* *}$ & $0,0001 * *$ \\
\hline Rep & 2 & 0,3483 & 0,5402 & 0,2986 & 0,000007 \\
\hline Resíduo & 22 & 0,2018 & 0,1699 & 3,8263 & 0,000002 \\
\hline $\mathrm{CV}(\%)$ & & 11,53 & 23,69 & 9,77 & 9,17 \\
\hline Média & & 3,8974 & 1,7401 & 20,0138 & 0,0132 \\
\hline
\end{tabular}

Quanto à massa seca parte aérea (Figura 1A) o modelo quadrático foi o que melhor se ajustou a curva sem inoculação, apresentando coeficientes de determinação de $75 \%$. O maior valor foi observado na dose $120 \mathrm{~kg} \mathrm{ha}^{-1} \mathrm{P}_{2} \mathrm{O}_{5}$, revelou que o valor máximo estimado foi de 4,96 $\mathrm{g}$ de massa seca da parte aérea, porém, a menor quantidade de massa seca da parte aérea foi estimada em $2,93 \mathrm{~g}$, obtida na ausência da aplicação de fósforo $\left(0 \mathrm{~kg} \mathrm{ha}^{-1} \mathrm{de}\right.$ $\mathrm{P}_{2} \mathrm{O}_{5}$ ). Corroborando Fernandes et al. (2013), o aumento no teor de P no solo aumentou a produção de massa seca da parte aérea do caupi, nas doses mais baixas e teores intermediários, onde também ocorreu curva quadrática em experimento para estudo da produtividade de feijão-caupi em função da calagem e fósforo em condições de campo de cultivo. Torquato et al. (2011), verificaram em seu trabalho que os teores de cálcio na folha, resultou no aumento da massa seca da parte aérea, em todos os tratamentos sob as diferentes doses de fósforo. Desta pode infere-se que a disponibilidade de fósforo pode desencadear mudanças na fotossíntese, pois o P atua como agente formador da molécula de ATP. Baixa produção de ATP afeta diretamente no crescimento das plantas. Podendo até resultar em desequilíbrios de outros minerais, como o cálcio. 

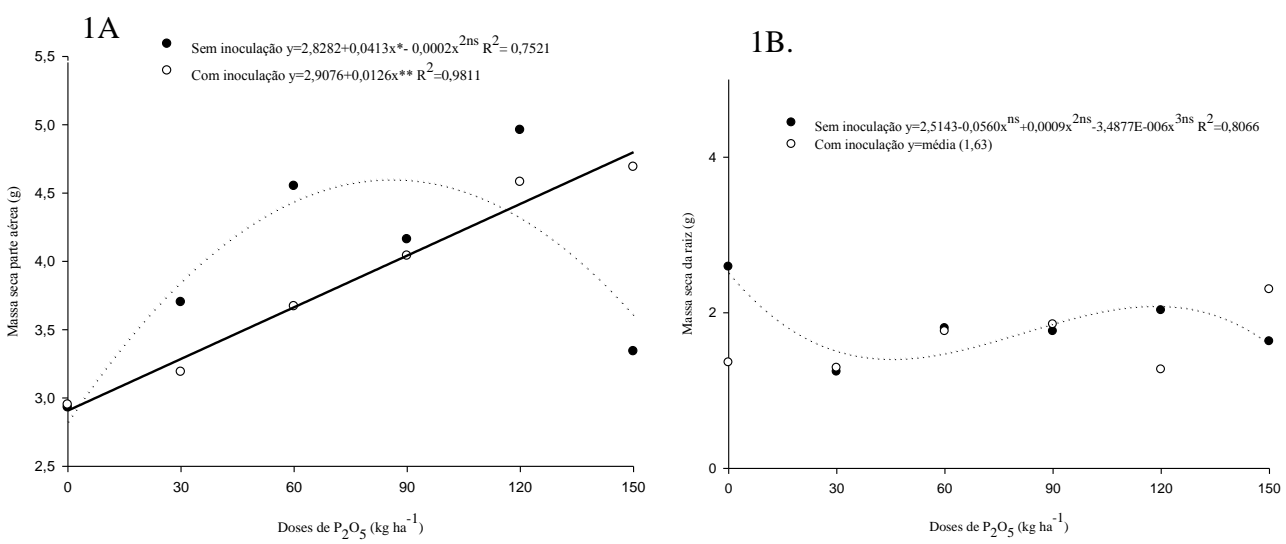

$1 \mathrm{C}$

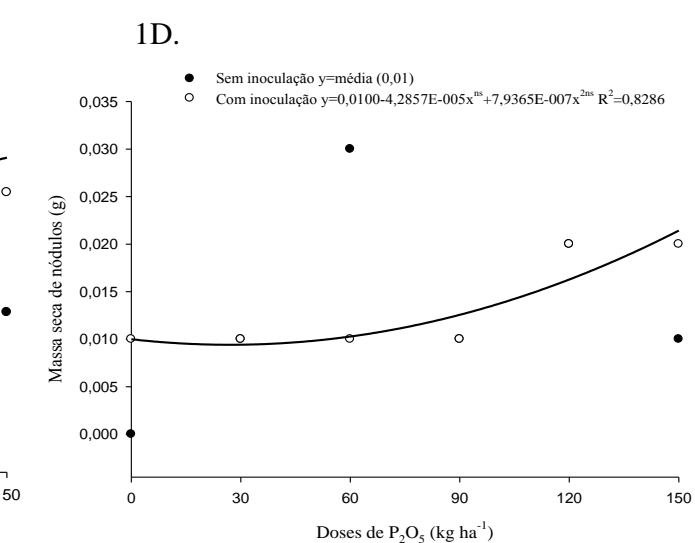

Figura 1. 1A. Massa seca da parte aérea, Figura 1B. Massa seca da raiz, Figura 1C. Número de nódulos, e Figura 1D. Massa seca dos nódulos, em função da interação entre doses de fósforo com e sem inoculação em casa de vegetação Gurupi - TO, 2015.

Para a característica massa seca da raiz em função da interação entre doses de fósforo e inoculação (Figura 1B), a análise de regressão cúbica foi a que melhor se ajustou a curva sem inoculação, apresentando coeficiente de regressão de $80 \%$. Foi observada maior massa seca das raízes na ausência de aplicação de fósforo $\left(0 \mathrm{~kg} \mathrm{ha}^{-1} \mathrm{P}_{2} \mathrm{O}_{5}\right)$ seguida pela dose de $120 \mathrm{~kg} \mathrm{ha}^{-1} \mathrm{P}_{2} \mathrm{O}_{5}$, com valores estimados de 2,59 e 2,03 g, respectivamente. Estes resultados estão de acordo com Fageria (1998) que observou o comprimento máximo das raízes ocorreu no nível mínimo de $\mathrm{P}$ e diminuiu com o aumento de nível de $\mathrm{P}$ no solo, significando que em solos deficientes em $\mathrm{P}$, as raízes crescem mais para explorar o maior volume de solo e para satisfazer a necessidade nutricional da planta. Ou seja, o estresse nutricional, força as raízes a crescerem. Já em solos bem adubados as raízes crescem mais, devido à boa disponibilidade de nutrientes (ambiente sem estresse), que é fator determinante para o desenvolvimento vegetal.

Já para a curva com inoculação ainda na Figura 1B, não se ajustou a nenhum modelo de regressão, devido à natureza dos dados. Para estes, a maior massa seca das raízes foi encontrada na dose de $150 \mathrm{~kg} \mathrm{ha}^{-1} \mathrm{P}_{2} \mathrm{O}_{5}$ com valor estimado de 2,3 g. Indicando que a alta adubação com $\mathrm{P}$, não afetou negativamente a massa seca das raízes inoculadas com rizóbio. Provavelmente o efeito positivo do $\mathrm{P}$ se deve ao aumento dos pelos radiculares da planta, 
que por sua vez são locais de infecção das bactérias do rizóbio, então, em ambiente com pouca disponibilidade de fósforo, a bactéria tem sua eficiência limitada, pela falta de locais de infecção (PEREIRA, 2008). Estes diferem dos resultados encontrados por Silva et al. (2010) onde o valor máximo estimado para a massa seca das raízes foi de $0,41 \mathrm{~g} \mathrm{planta}^{-1}$ nas doses de $61 \mathrm{~kg} \mathrm{P}_{2} \mathrm{O}_{5} \mathrm{ha}^{-1}$, com super fosfato simples. As menores massas secas de raízes foram observadas nas doses 30 e $120 \mathrm{~kg} \mathrm{ha}^{-1} \mathrm{P}_{2} \mathrm{O}_{5}$, com valores estimados de 1,29 e 1,27 g, respectivamente. Isto indica o efeito favorável do $\mathrm{P}$ no crescimento do sistema radicular.

No número de nódulos (Figura 1C), para a fonte de variação interação entre doses e inoculação, nos tratamentos sem inoculação apresentou melhor adequação a curva de regressão quadrática com coeficiente de $80 \%$. Nesta curva, houve influência positiva da adubação fosfatada, pois conforme aumenta as doses de fósforo, também ocorreu elevação do número de nódulos até o pico máximo na dose $60 \mathrm{~kg} \mathrm{ha}^{-1} \mathrm{P}_{2} \mathrm{O}_{5}$ com resultado estimado de 27 nódulos em duas plantas. As doses de fósforo crescentes induziram o aumento do número de nódulos das raízes, possivelmente por que o fósforo é fonte de energia para a planta (ATP) que quando bem nutrida, disponibiliza carboidratos para as bactérias de rizóbio auxiliando assim no desenvolvimento dos nódulos, até certo limite de adubação. Acima deste nível de adubação, a planta deixa de fazer simbiose com a bactéria, pois entende que não necessita mais deste mecanismo, que promove gasto de energia, porque existe disponibilidade de nutrientes no solo adequada para seu desenvolvimento, consequência disso é a redução do número de nódulos produzidos.

Quando inoculado, a curva de regressão que mais se ajustou foi à quadrática com coeficiente de 76\% (Figura 1C). Observou-se que com exceção da dose $60 \mathrm{~kg} \mathrm{ha}^{-1} \mathrm{P}_{2} \mathrm{O}_{5}$, houve um aumento no número de nódulos conforme se aumenta as doses de fósforo, com contagem máxima estimada de 31 nódulos na dose de $120 \mathrm{~kg} \mathrm{ha}^{-1} \mathrm{P}_{2} \mathrm{O}_{5}$. Provavelmente quando inoculada, a planta aproveita melhor os nutrientes do solo, através da simbiose com o rizóbio, e este por sua vez promove maior infecção na planta, que vai gerar mais nódulos de infecção. Resultados diferentes foram reportados por Silva et al. (2010) que observaram função quadrática e obteve valores máximos estimados de 46 nódulos na dose de $32,5 \mathrm{~kg} \mathrm{ha}^{-}$ ${ }^{1}$ de $\mathrm{P}_{2} \mathrm{O}_{5}$ em estudo do feijão-caupi sob diferentes doses e fontes de fósforo solúvel, o que pode estar ligado a diferença das bactérias, que possuem eficiência de FBN distintas. $\mathrm{O}$ menor resultado visto foi no tratamento $0 \mathrm{~kg} \mathrm{ha}^{-1} \mathrm{P}_{2} \mathrm{O}_{5}$.

Resultados semelhantes foram vistos por Araújo et al. (2009) em estudo sobre coinoculação rizóbio e Bacillus subtilis em feijão-caupi e leucena no estado do Piauí em casa de vegetação, que também encontraram maiores quantidades de nódulos em tratamentos que receberam inoculação com rizóbio.

A massa seca de nódulos (Figura 1D), para a curva sem inoculação, não se ajustou a nenhum modelo de regressão, desta forma $\mathrm{y}=$ média $(0,01)$. Esta curva apresentou valor máximo estimado de massa seca dos nódulos de $0,03 \mathrm{~g}$ na dose de $60 \mathrm{~kg} \mathrm{ha}^{-1} \mathrm{P}_{2} \mathrm{O}_{5}$.

Cultura Agronômica, Ilha Solteira, v.27, n.2, p.273-286, 2018 
$\mathrm{Na}$ curva com inoculação ainda na Figura 1D, ajustou-se melhor ao modelo de regressão quadrática, com coeficientes cerca de $82 \%$, houve desenvolvimento constante da massa seca dos nódulos conforme se elevou as doses de fósforo, onde o máximo de massa seca estimado foi de $0,02 \mathrm{~g}$ para a partir da dose $120 \mathrm{~kg} \mathrm{ha}^{-1} \mathrm{P}_{2} \mathrm{O}_{5}$. Isto pode ser explicado pela ação do fósforo na regulação, ativação e desativação enzimática nas membranas celulares, ou seja, quanto mais fósforo mais regulação e mais ativação das enzimas, resultando em mais energia para a planta, que consequentemente poderá se manter e se relacionar com outros indivíduos como na simbiose com o rizóbio. Resultados diferentes foram reportados por Silva et al. (2010) que observaram função quadrática e obteve valores máximos estimados de $100 \mathrm{mg}_{\text {planta }}^{-1}$ na dose de $53 \mathrm{~kg} \mathrm{ha}^{-1}$ de $\mathrm{P}_{2} \mathrm{O}_{5}$ da fonte super fosfato simples em estudo do feijão-caupi sob diferentes doses e fontes de fósforo solúvel. E a menor massa seca de nódulo estimado $(0,01 \mathrm{~g})$ ocorreu até a dose $90 \mathrm{~kg} \mathrm{ha}^{-1} \mathrm{P}_{2} \mathrm{O}_{5}$.

De acordo com os resultados da análise de variância na Tabela 2, observa-se que houve efeito significativo na interação para todas as características avaliadas, evidenciando que os fatores são dependentes, ao nível de $1 \%$ de probabilidade pelo teste $\mathrm{F}$.

Tabela 2. Resumo da análise de variância das características massa seca da parte aérea (MSPA), massa seca da raiz (MSR), número de nódulos (NN) e massa seca dos nódulos (MSN) de feijão-caupi, submetidos a doses de fósforo com e sem inoculação em campo na safra 2014/2015, Gurupi - Tocantins.

\begin{tabular}{lccccc}
\hline \multirow{2}{*}{ Fonte Variação } & \multirow{2}{*}{ GL } & \multicolumn{4}{c}{ QM } \\
\cline { 3 - 6 } & & MSPA $(\mathrm{g})$ & MSR $(\mathrm{g})$ & $\mathrm{NN}(\mathrm{uni})$ & MSN $(\mathrm{g})$ \\
\hline Doses de P (D) & 5 & $1383,8490^{* * *}$ & $27,0642^{* *}$ & $3193,5208^{* *}$ & $0,0026^{* *}$ \\
Inoculação (I) & 1 & $2,0307^{\mathrm{ns}}$ & $1,5272^{*}$ & $24435,1875^{* *}$ & $0,0064^{* *}$ \\
(D x I) & 5 & $568,2219^{* *}$ & $10,3480^{* *}$ & $933,7875^{* *}$ & $0,0013^{* *}$ \\
Bloco & 3 & 3,3180 & 0,0494 & 3,1875 & 0,0003 \\
Resíduo & 33 & 2,1102 & 0,2371 & 3,5662 & 0,00007 \\
\hline CV (\%) & & 4,61 & 9,30 & 2,29 & 16,89 \\
\hline Média & & 31,5439 & 5,2342 & 82,6458 & 0,0495 \\
\hline
\end{tabular}

Para a característica massa seca da parte aérea em função da interação entre doses de fósforo e inoculação (Figura 2A), a análise de regressão quadrática foi a que melhor se ajustou aos dados da curva sem inoculação, apresentando coeficiente de regressão de $89 \%$. Nesta, a dose que mais resultou em massa seca da parte aérea foi $60 \mathrm{~kg} \mathrm{ha}^{-1} \mathrm{P}_{2} \mathrm{O}_{5}$, com valor estimado de 48,51 g. Diferindo do encontrado por Araújo et al. (2009) que com adubação de $60 \mathrm{~kg} \mathrm{ha}^{-1}$ de $\mathrm{P}_{2} \mathrm{O}_{5}$ constataram apenas $4,8 \mathrm{~g}$ de massa seca da parte aérea por planta. Tal resultado pode ser explicado pelo ambiente em que foram desenvolvidos ambos os trabalhos casa de vegetação e campo. Pois á campo a área de solo explorada pela planta é maior o que pode proporcionar maior espaço físico para a planta se desenvolver.

Cultura Agronômica, Ilha Solteira, v.27, n.2, p.273-286, 2018 
$2 \mathrm{~A}$.

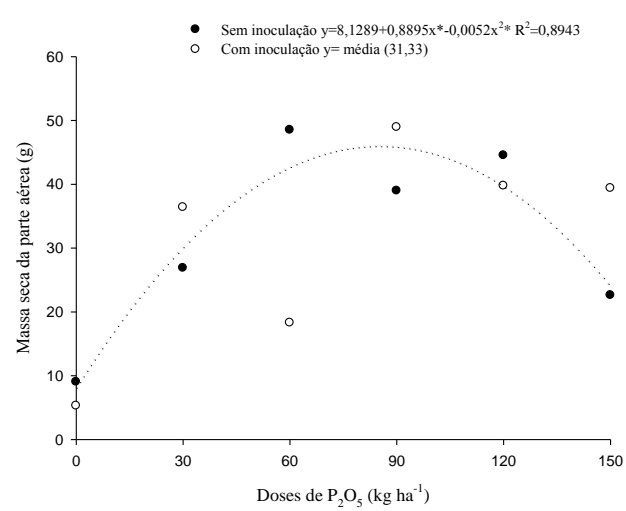

2C.

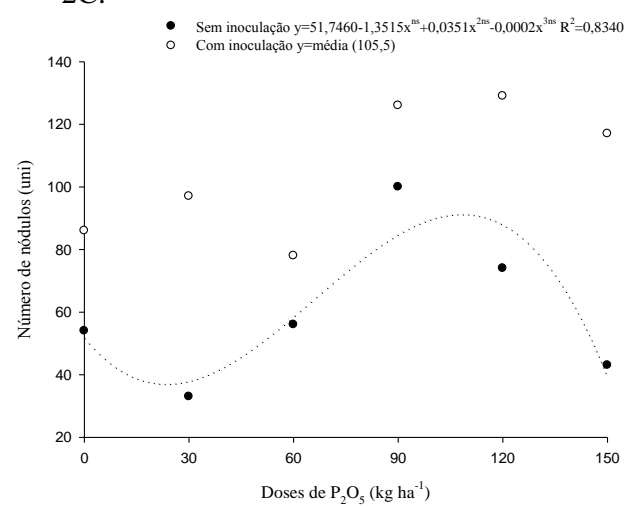

$2 B$.

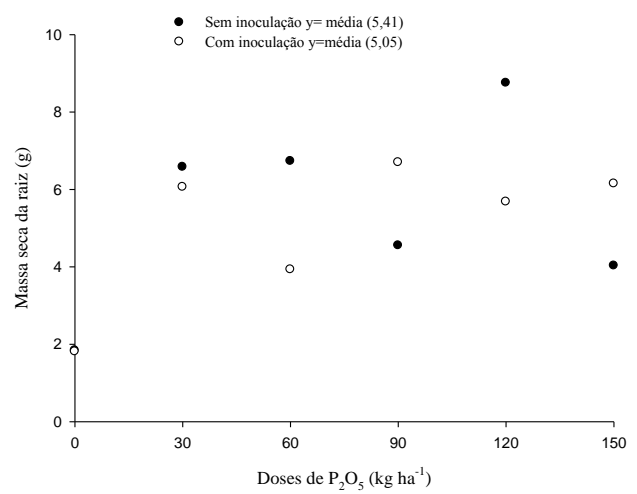

2D.

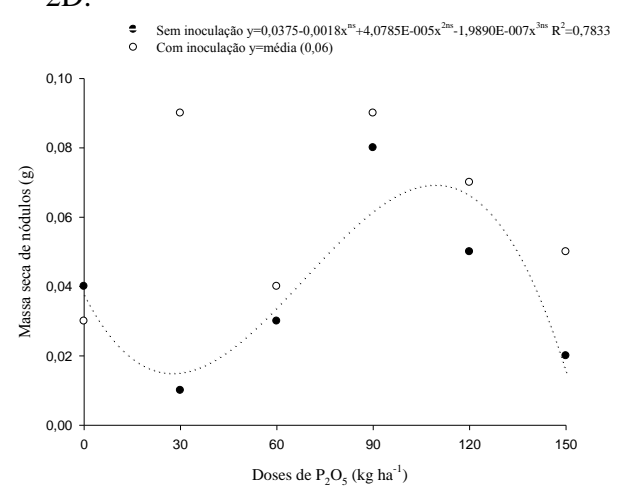

Figura 2. 2A. Massa seca da parte aérea, Figura 2B. Massa seca raiz, Figura 2C. Número de nódulos, Figura 2D. Massa seca de nódulos de feijão-caupi BRS Novaera, em função da interação entre doses de fósforo com e sem inoculação de rizóbio, na safra 2014/2015 em Gurupi - TO.

Fernandes et al. (2013) constataram que a adição e o aumento no teor de P no solo, aumentou a produção de massa seca da parte aérea do caupi, para doses mais baixas e teores intermediários. Porém a dose estimada de $45 \mathrm{~kg} \mathrm{ha}^{-1}$ de $\mathrm{P}_{2} \mathrm{O}_{5}$ foi a que propiciou maior produção de massa seca da parte aérea. Tal resultado pode estar relacionado à baixa disponibilidade de $\mathrm{P}$ no solo antes da adubação $\left(0,5 \mathrm{mg} \mathrm{dm}^{-3}\right)$, quando comparado ao teor inicial de $\mathrm{P}$ no solo do trabalho de Fernandes et al. (2013) que foi bem superior $(23,4 \mathrm{mg}$ $\mathrm{dm}^{-3}$ ), o que pode ter causado um efeito de compensação. Os teores de $\mathrm{P}$ disponível no solo de $15 \mathrm{mg} \mathrm{dm}^{-3}$ podem ser considerados altos para a cultura do feijão-caupi (CRAVO e SOUZA, 2010).

A curva com inoculação na Figura 2A não se ajustou a nenhum modelo de regressão. Para os tratamentos com inoculação a maior massa seca da parte aérea foi encontrada na dose de $90 \mathrm{~kg} \mathrm{ha}^{-1} \mathrm{P}_{2} \mathrm{O}_{5}$ com valor estimado de 48,94 g, isto demonstra que o rizóbio auxiliou na disponibilização do $\mathrm{P}$ até em doses altas desse nutriente, provavelmente retardando o efeito de estresse salino nas raízes do feijão-caupi.

Segundo Heckrath et al. (1995), a mobilidade de P em um solo deverá aumentar com a saturação da superfície de adsorção, com a consequente diminuição da energia de ligação, o 
que proporciona maior dessorção de $\mathrm{P}$ do solo. Desta forma, a maior quantidade de $\mathrm{P}$ no solo em dessorção, até a dose limite de $90 \mathrm{~kg} \mathrm{ha}^{-1} \mathrm{P}_{2} \mathrm{O}_{\mathrm{s}}$ disponibilizou mais fósforo para o desenvolvimento da parte aérea, possivelmente porque o $\mathrm{P}$ tem função marcante na atividade da fotossíntese (FSI), no ciclo de Calvin entres outras atividades, que vão gerar carboidratos e oxigênio, essenciais para o desenvolvimento da parte aérea da planta.

Chagas Júnior et al. (2010) estudando a eficiência agronômica de estirpes de rizóbio inoculadas, observaram média de 14,22 g de massa seca da parte aérea, o que difere do encontrado neste trabalho, que obteve média estimada de $31,33 \mathrm{~g}$, com mesma cultivar e mesma região. Isto possivelmente pode estar relacionado á época de realização de ambos os experimentos, pois o de Chagas Júnior et al. (2010) foi realizado de março a maio (final do período chuvoso nesta região) isso pode ter causado um déficit hídrico neste experimento. Já este trabalho foi realizado em final de outubro a janeiro (início do período chuvoso), o que pode ter favorecido o melhor desenvolvimento da parte aérea da planta. O mesmo ocorre em Chagas Júnior et al. (2012) com $6 \mathrm{~g}$ de massa seca da parte aérea no tratamento adubado com $80 \mathrm{~kg} \mathrm{ha}^{-1} \mathrm{P}_{2} \mathrm{O}_{5}$.

Para a característica massa seca das raízes em função da interação entre doses de fósforo e inoculação (Figura 2B), nenhum dos modelos de regressão testados se ajustaram aos dados da curva sem inoculação. Nesta, a dose que mais resultou em massa seca das raízes foi $120 \mathrm{~kg} \mathrm{ha}^{-1} \mathrm{P}_{2} \mathrm{O}_{5}$, com valor estimado de 8,75 g. Adubações abaixo desta dose não foram suficientes para proporcionar a máxima massa seca de raízes, possivelmente, porque as doses de $\mathrm{P}_{2} \mathrm{O}_{5}$ aplicados não forneceram $\mathrm{P}$ suficiente, para a planta expressar seu máximo desenvolvimento, devido a algum estresse nutricional leve de $\mathrm{P}$ mineral. $\mathrm{E}$ adubações superiores foram pouco prejudiciais, pois na referida época do experimento houve poucas chuvas, que podem ter deixado o solo salino próximo às raízes, e devido ao ajuste osmótico, a planta deixou de absorver este mineral. $\mathrm{O}$ menor resultado foi no tratamento $0 \mathrm{~kg} \mathrm{ha}^{-1} \mathrm{P}_{2} \mathrm{O}_{5}$ com valor estimado menor que $1,84 \mathrm{~g}$ de massa seca de raiz, isto pode ter ocorrido, devido à limitada disponibilidade de $\mathrm{P}$ para as raízes. Este resultado é superior aos observados por Chagas Júnior et al. (2012) e Chagas Júnior et al. (2014) que verificaram média de massa seca de raiz de 1,3 e 3,3 g, respectivamente, com adubação de $80 \mathrm{~kg} \mathrm{ha}^{-1} \mathrm{P}_{2} \mathrm{O}_{5}$.

A curva com inoculação na Figura 2B não se ajustou a nenhum modelo de regressão. Para os tratamentos com inoculação a maior massa seca das raízes foi encontrada na dose de $90 \mathrm{~kg} \mathrm{ha}^{-1} \mathrm{P}_{2} \mathrm{O}_{5}$ com valor estimado de $6,7 \mathrm{~g}$, isto demonstra que o rizóbio auxiliou na disponibilização do $\mathrm{P}$ até em doses altas desse nutriente, provavelmente retardando o efeito de estresse salino nas raízes do feijão-caupi, visto que no período de desenvolvimento deste trabalho, ocorreu déficit de chuvas nesta região. E a menor massa seca de raízes foi observada no tratamento $0 \mathrm{~kg} \mathrm{ha}^{-1} \mathrm{P}_{2} \mathrm{O}_{5}$, estimada em $1,81 \mathrm{~g}$, provavelmente pela falta de nutrientes disponível no solo para o adequado desenvolvimento radicular. Resultados diferentes foram visualizados por Chagas Júnior et al. (2014) avaliando eficiência da inoculação combinada de rizóbio e Trichoderma spp. em diferentes cultivares de feijãocaupi na época da safrinha. Devido às condições de clima seco e quente, como registrado no

Cultura Agronômica, Ilha Solteira, v.27, n.2, p.273-286, 2018 
momento de realização deste experimento, o rizóbio pode ter sofrido também estresse, pois apesar de ser uma bactéria de solo, ela até pode tolerar altas temperaturas, porém não se desenvolve com deveria. Isto influência na sua capacidade de sobreviver e de promover simbiose com outros organismos.

O presente estudo também está de acordo com resultados reportados por Gualter et al. (2008) observando doses de P, K e Mo na cultura do feijão-caupi inoculado em neossolo flúvico.

O número de nódulos (Figura 2C), para a fonte de variação interação, apresentou curva de regressão cúbica para os tratamentos sem inoculação e coeficiente de $83 \%$. Estes foram influenciados conforme aumentou-se as doses de fósforo, com pico máximo de número de nódulos na dose $90 \mathrm{~kg} \mathrm{ha}^{-1} \mathrm{P}_{2} \mathrm{O}_{5}$ com estimativa de 100 nódulos em duas plantas. Apesar de não inoculada, esta curva apresentou nodulação até mesmo na dose zero de $\mathrm{P}$, isto é uma indicação da alta capacidade dos rizóbios estabelecidos no solo nodularem as plantas de feijão-caupi, como é frequentemente observado (HARA e OLIVEIRA, 2004; ZHANG et al., 2007). A respeito das doses $\mathrm{P}$ aplicadas à dose $90 \mathrm{~kg} \mathrm{ha}^{-1} \mathrm{P}_{2} \mathrm{O}_{5}$ foi a mais propicia para $\mathrm{o}$ desenvolvimento de nódulos de raízes de feijão-caupi não inoculado, não afetando na sobrevivência e no desenvolvimento nem da planta e nem do microrganismo no solo. Resultado semelhante foi observado por Zilli et al. (2009) e Chagas Júnior et al. (2014) com valor de 37 e 27 nódulos por planta, respectivamente, encontrados na aplicação da dose 80 $\mathrm{kg} \mathrm{ha}^{-1} \mathrm{P}_{2} \mathrm{O}_{5}$.

Quando inoculado (Figura 2C), a curva não se ajustou a nenhum modelo de regressão. Observou-se que com exceção da dose $60 \mathrm{~kg} \mathrm{ha}^{-1} \mathrm{P}_{2} \mathrm{O}_{5}$, houve um aumento no número de nódulos conforme se aumentava as doses de fósforo, com contagem máxima estimada na dose de $120 \mathrm{~kg} \mathrm{ha}^{-1} \mathrm{P}_{2} \mathrm{O}_{5}$ com 129 nódulos. O que observa-se é que a adubação com $\mathrm{P}$ auxilia na simbiose, possivelmente porque quanto mais se aplica o nutriente, mais há a formação de nódulos nas raízes, indicando assim que está ocorrendo simbiose bactériaplanta. Isto pode estar ligado a melhor nutrição da planta, que obtém mais ATP, do fósforo, e com isto pode promover simbiose com esta bactéria, liberando para este mais carbono. Resultado diferente do encontrado por Zilli et al. (2009), com 62 nódulos na dose $80 \mathrm{~kg} \mathrm{ha}^{-1}$ $\mathrm{P}_{2} \mathrm{O}_{5}$. O menor resultado visto foi no tratamento $0 \mathrm{~kg} \mathrm{ha}^{-1} \mathrm{P}_{2} \mathrm{O}_{5}$. Apesar da limitada quantidade deste nutriente no solo, foi possível o desenvolvimento de nódulos, muito provavelmente pela capacidade do rizóbio solubilizar fosfato não lábil do solo e liberar para a planta.

Na massa seca de nódulos (Figura 2D), para a fonte de variação interação, apresentou curva de regressão cúbica para os tratamentos sem inoculação e coeficiente de $78 \%$. Estes foram influenciados conforme aumentou-se as doses de fósforo, variando a massa, com pico máximo de $0,08 \mathrm{~g}$ na dose $90 \mathrm{~kg} \mathrm{ha}^{-1} \mathrm{P}_{2} \mathrm{O}_{5}$.Possivelmente porque a partir dessa dose $\mathrm{o}$ acúmulo de fósforo, seja prejudicial a formação dos nódulos. Devido à preferência pelo fósforo mineral disponível ao nitrogênio oriundo da simbiose no processo de fixação biológica do nitrogênio. Resultados diferentes foram reportados por Silva et al. (2010) que

Cultura Agronômica, Ilha Solteira, v.27, n.2, p.273-286, 2018 
observaram função quadrática e obteve valores máximos estimados de $100 \mathrm{mg}^{\text {planta }}{ }^{-1}$ na dose de $53 \mathrm{~kg} \mathrm{ha}^{-1}$ de $\mathrm{P}_{2} \mathrm{O}_{5}$ da fonte super fosfato simples em estudo do feijão-caupi sob diferentes doses e fontes de fósforo solúvel.

Quando inoculado (Figura 2D), a curva não se ajustou a nenhum modelo de regressão. Observou-se que, houve variação na massa seca de nódulos conforme se aumentava as doses de fósforo, com contagem máxima estimada na dose de 30 e $90 \mathrm{~kg} \mathrm{ha}^{-1} \mathrm{P}_{2} \mathrm{O}_{5}$ com 0,09 g.

\section{CONCLUSÃO}

Em casa de vegetação a inoculação com rizóbio apresentou resposta linear para a massa seca da parte aérea e quadrática, para número e massa seca de nódulos.

A dose de fósforo que propiciou a máxima produção de massa seca da parte aérea e massa seca da raiz foi de $120 \mathrm{~kg} \mathrm{ha}^{-1}$ de $\mathrm{P}_{2} \mathrm{O}_{5}$, sem inoculação com rizóbio.

Em campo nenhuma das características avaliadas se ajustaram aos modelos de regressão, quando inoculadas com rizóbio.

Na massa seca da parte aérea foi observado efeito quadrático e máximo de 48,51 g na dose de $60 \mathrm{~kg} \mathrm{ha}^{-1}$ de $\mathrm{P}_{2} \mathrm{O}_{5}$ sem inoculação.

O número e massa seca de nódulos foram superiores quando aplicado $90 \mathrm{~kg} \mathrm{ha}^{-1} \mathrm{de}$ $\mathrm{P}_{2} \mathrm{O}_{5}$ sem inoculação e ajuste cúbico da curva de regressão.

\section{AGRADECIMENTOS}

Ao CNPq.

\section{REFERÊNCIAS BIBLIOGRÁFICAS}

ARAÚJO, A. S. F.; CARNEIRO, R. F. V.; BEZERRA, A. A. C.; ARAÚJO, F. F. Coinoculação rizóbio e Bacillus subtilis em feijão-caupi e leucena: efeito sobre a nodulação, a fixação de $\mathrm{N}_{2}$ e o crescimento das plantas. Ciência Rural, Santa Maria, v. 40, n. 1, 2009. Disponível em: <http://www.scielo.br/scielo.php?script=sci_arttext\&pid=S010384782010000100029>. Acesso em: 06 abr. 2018.

BASTOS, A. L.; COSTA, J. P. V.; SILVA, I. F.; RAPOSO, R. W. C.; OLIVEIRA, F. A.; ALBUQUERQUE, A. W. Resposta do milho a doses de fósforo. Revista Brasileira de Engenharia Agrícola e Ambiental, Campina Grande, v. 14, n. 5, p.485-491, 2010.

BURITY, H. A.; LYRA, M. C. C. P.; SOUZA, E. S. Efetividade da inoculação com rizóbio e fungos micorrízicos arbusculares em mudas de sabiá submetidas a diferentes níveis de fósforo. Pesquisa Agropecuária Brasileira, Brasília, v. 35, n. 4, p.801-807, 2000.

Cultura Agronômica, Ilha Solteira, v.27, n.2, p.273-286, 2018 
CHAGAS JÚNIOR, A. F.; OLIVEIRA, A. G.; REIS, H. B.; SANTOS, G. R.; CHAGAS, L. F. B.; MILLER, L. O. Eficiência da inoculação combinada de rizóbio e Trichoderma spp. em diferentes cultivares de feijão-caupi (Vigna unguiculata) no cerrado (Savana Brasileira). Revista de Ciências Agrárias, Lisboa, v. 37, n. 1, p.20-28, 2014.

CHAGAS JÚNIOR, A. F.; RAHMEIER, W.; FIDELIS, R. R.; SANTOS, G. R.; CHAGAS, L. F. B. Eficiência agronômica de estirpes de rizóbio inoculadas em feijão-caupi no Cerrado, Gurupi- TO. Revista Ciência Agronômica, Fortaleza, v. 41, n. 4, p.709-714, 2010.

CHAGAS JÚNIOR, A. F.; SANTOS, G. R.; REIS, H. B.; MILLER, L. O.; CHAGAS, L. F. B. Resposta de feijão-caupi a inoculação com rizóbio e Trichoderma sp. no cerrado, Gurupi, TO. Revista Verde, Mossoró, v. 7, n. 2, p.242-249, 2012.

CRAVO, M. S.; SOUZA, B. D. L. Recomendação de Adubação e Calagem para Culturas Anuais - Feijão-Caupi. In: CRAVO, M. S.; VIÉGAS. I. J. M.; BRASIL, E. C. (Org.). Recomendações de adubação e calagem para o Estado do Pará. 1. ed. Belém: Embrapa Amazônia Oriental, 2010, cap. 5, v. 1, p. 147-149.

GUAlTER, R. M. R.; LEITE, L. F. C.; ARAÚJO, A. S. F.; AlCANTARA, R. M. C. M.; COSTA, D. B. Inoculação e adubação mineral em feijão-caupi: efeitos na nodulação, crescimento e produtividade. Scientia Agraria, Curitiba, v. 9, n. 4, p.469-474, 2008.

SANTOS, H. G.; JACOMINE, P. K. T.; ANJOS, L. H. C.; OLIVEIRA, V. Á.; LUMBRERAS, J. F.; COELHO, M. R.; ALMEIDA, J. A.; CUNHA, T. J. F.; OLIVEIRA, J. B. Sistema Brasileiro de Classificação de Solos. 3 ed. rev. ampl. Brasília: Embrapa Solos, 2013. $353 \mathrm{p}$.

EMPRESA BRASILEIRA DE PESQUISA AGROPECUÁRIA - EMBRAPA. Produtos, Processos e Serviços. Feijão-caupi BRS Novaera. Brasília. 2007. Disponível em: $<$ https://www.embrapa.br/busca-de-produtos-processos-e-servicos/-/produto-servico /1451/feijao-caupi-brs-novaera>. Acesso em: 05 jan. 2018.

FAGERIA, N. K. Eficiência de uso de fósforo pelos genótipos de feijão. Revista Brasileira Engenharia Agrícola Ambiental, Campina Grande, v. 2, n. 2, p.128-131, 1998.

FAGERIA, N. K.; BARBOSA FILHO, M. P.; STONE, L. F. Resposta do feijoeiro a adubação fosfatada. Informações Agronômicas, Piracicaba, n. 102, p.1-9, 2003.

FERNANDES, A. R.; FONSECA, M. R.; BRAZ, A. M. S. Produtividade de feijão-caupi em função da calagem e fósforo. Revista Caatinga, Mossoró, v. 26, n. 4, p.54-62, 2013.

FERREIRA, D. F. SISVAR: a computer statistical analysis system. Ciência e Agrotecnologia, Lavras, v. 35, n. 6, p.1039-1042, 2011.

FONSECA, M. R.; FERNANDES, A. R.; SILVA, G. R.; BRASIL, E. C. Teor e acúmulo de nutrientes por plantas de feijão-caupi em função do fósforo e da saturação por bases. Revista Ciências Agrárias, Belém, v. 53, n. 2, p.195-205, 2010.

Cultura Agronômica, Ilha Solteira, v.27, n.2, p.273-286, 2018 
HARA, F. A. S.; OLIVEIRA, L. A. Características fisiológicas e ecológicas de isolados de rizóbios oriundos de solos ácidos e álicos de Presidente Figueiredo, Amazonas. Acta Amazônica, Amazonas, v. 34, n. 3, p.343-357, 2004.

HECKRATH, G.; BROOKES, P. C.; POULTON, P. R.; GOUDING, K. W. T. Phosphorus leaching from soils containing different phosphorus concentrations in the Broaadbalk experiment. Journal Environment Quality, Madison, v. 24, n. 1, p.904-910, 1995.

PEREIRA, P. M. Taxonomia e diversidade genética de rizóbios microssimbiontes de distintas leguminosas com base na análise polifásica (BOX-PCR e 16S RNAr) e na metodologia de MLSA. 2008. 100 f. Tese (Doutorado em Microbiologia) - Universidade Estadual de Londrina, Londrina, 2008.

ROCHA, W. S.; SAKAI, T. R.; SOUZA, D. L. A.; CHAGAS JÚNIOR, A. F.; SANTOS, M. M. Efeito da microbiolização na germinação e crescimento inicial de feijão caupi no Estado do Tocantins. Tecnologia \& Ciência Agropecuária, João Pessoa, v. 11, n. 6, p.41-47, 2017.

SILVA, E. F. L.; ARAÚJO, A. S. F.; SANTOS, V. B.; NUNES, L. A. P. L.; CARNEIRO, R. F. V. Fixação biológica do $\mathrm{N}_{2}$ em feijão-caupi sob diferentes doses e fontes de fósforo solúvel. Bioscience Journal, Uberlândia, v. 26, n. 3, p.394-402, 2010.

TORQUATO, J. P.; AQUINO, B. F.; SOUSA, G. G.; GUIMARÃES, F. V. A.; ANJOS, D. C. Teores de $\mathrm{Ca}, \mathrm{K}, \mathrm{Mg}$ e $\mathrm{P}$ na cultura do feijão-caupi sob diferentes doses de fósforo. Agropecuária Técnica, Areia, v. 32, n. 1, p.79-87, 2011.

VINCENT, J. M. Manual for the pratical study of root nodule bacteria. Oxford: Blackwll, 1970. 164 p.

ZHANG, W. T.; YANG, J. K.; YUAN, T. Y.; ZHOU, J. C. Genetic diversity and phylogeny of indigenous rhizobia from cowpea [Vigna unguiculata (L.) Walp.]. Biology and Fertility of Soils, Firenze, v. 44, n. 1, p.201-210, 2007.

ZILLI, J. É.; MARSON, L. C.; MARSON, B. F.; RUMJANEK, N. G.; XAVIER, G. R. Contribuição de estirpes de rizóbio para o desenvolvimento e produtividade de grãos de feijão-caupi em Roraima. Acta Amazônica, Amazonas, v. 39, n. 4, p.749-758, 2009.

ZILli, J. É.; XAVIER, G. R.; RUMJANEK, N. G. BR 3262: Nova estirpe de Bradyrhizobium para a inoculação de feijão-caupi em Roraima. Boa Vista: Embrapa Roraima, 2008. 7 p. (Comunicado técnico, 10). 